PREPARED FOR THE U.S. DEPARTMENT OF ENERGY, UNDER CONTRACT DE-AC02-76CH03073

PPPL-3959

PPPL-3959

UC-70

\title{
Methane Screening \\ in JET Reverse Field Experiments
}

by

J.D. Strachan, B. Alper, G. Corrigan, S.K. Erents, C. Giroud, A. Korotkov, H. Leggate, G.F. Mathews, R.A. Pitts, M. Stamp, and J. Spence

May 2004

NM|

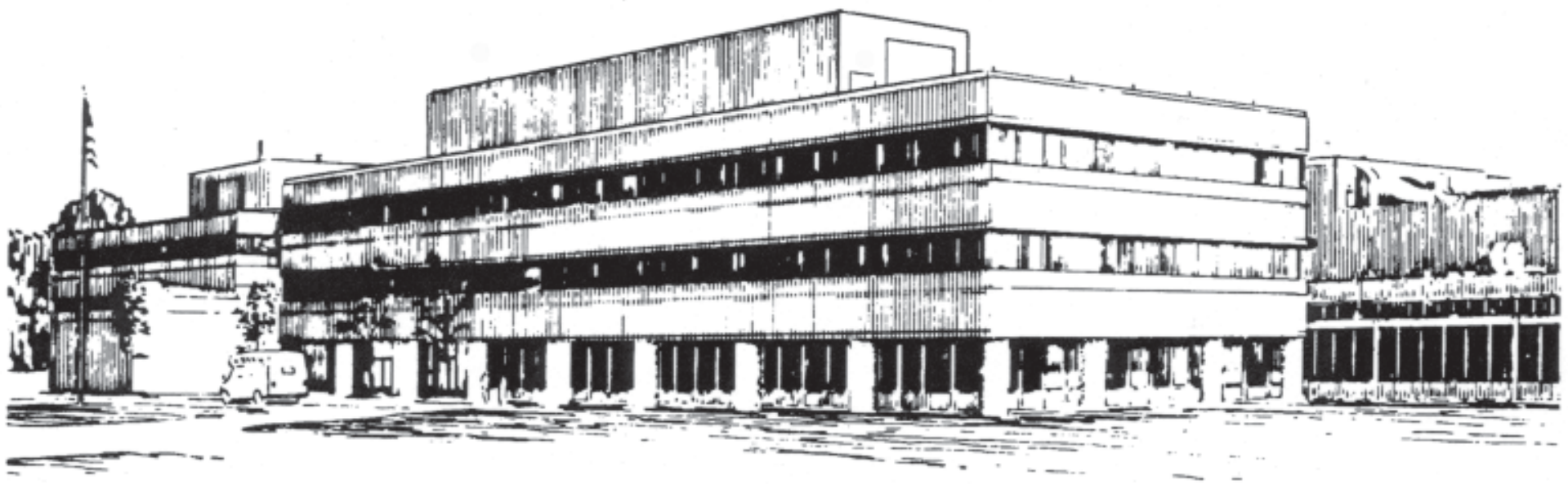

PRINCETON PLASMA PHYSICS LABORATORY PRINCETON UNIVERSITY, PRINCETON, NEW JERSEY 


\section{PPPL Reports Disclaimer}

This report was prepared as an account of work sponsored by an agency of the United States Government. Neither the United States Government nor any agency thereof, nor any of their employees, makes any warranty, express or implied, or assumes any legal liability or responsibility for the accuracy, completeness, or usefulness of any information, apparatus, product, or process disclosed, or represents that its use would not infringe privately owned rights. Reference herein to any specific commercial product, process, or service by trade name, trademark, manufacturer, or otherwise, does not necessarily constitute or imply its endorsement, recommendation, or favoring by the United States Government or any agency thereof. The views and opinions of authors expressed herein do not necessarily state or reflect those of the United States Government or any agency thereof.

\section{Availability}

This report is posted on the U.S. Department of Energy's Princeton Plasma Physics Laboratory Publications and Reports web site in Fiscal Year 2004. The home page for PPPL Reports and Publications is: http://www.pppl.gov/pub_report/

DOE and DOE Contractors can obtain copies of this report from:

U.S. Department of Energy

Office of Scientific and Technical Information

DOE Technical Information Services (DTIS)

P.O. Box 62

Oak Ridge, TN 37831

Telephone: (865) 576-8401

Fax: (865) 576-5728

Email: reports@adonis.osti.gov

This report is available to the general public from:

National Technical Information Service

U.S. Department of Commerce

5285 Port Royal Road

Springfield, VA 22161

Telephone: $1-800-553-6847$ or

(703) $605-6000$

Fax: (703) 321-8547

Internet: http://www.ntis.gov/ordering.htm 


\section{Methane Screening in JET Reverse Field Experiments}

J.D.Strachan, B.Alper ${ }^{\mathrm{a}}$, G.Corrigan ${ }^{\mathrm{a}}$, S.K.Erents ${ }^{\mathrm{a}}$, C.Giroud, A.Korotkov ${ }^{\mathrm{a}}$, H.Leggate $^{\mathrm{a}}$, G.F.Mathews ${ }^{\mathrm{a}}$, R.A.Pitts ${ }^{\mathrm{b}}$, M.Stamp ${ }^{\mathrm{a}}$, and J.Spence ${ }^{\mathrm{a}}$

Plasma Physics Laboratory, Princeton University, Princeton, NJ08543, USA ${ }^{a}$ Euratom/UKAEA Fusion Association, Culham Science Centre, Abingdon, Oxon OX14 3DB,UK

${ }^{b}$ CRPP, Association EURATOM-Confederation Suisse, Ecole Polytechnique Federale de Lausanne, CH-1015 Lausanne, Switzerland 


\begin{abstract}
JET plasmas with reverse magnetic field feature a different SOL flow than those with normal field. The observed carbon fuelling efficiency from injecting methane gas was similar in reverse and normal field. EDGE2D modeling used an externally applied force to create the SOL flows, without specifying the origin of the force. The resulting flow agreed reasonably with the experimental values between the separatrix and $4 \mathrm{~cm}$ mid-plane depth in the SOL. The effect of the flow on the calculated carbon screening was 5 to $15 \%$ higher carbon fuelling efficiency for the low flow velocity with reverse field.
\end{abstract}




\section{Introduction}

Methane screening experiments [1] have been used to benchmark the effectiveness of the SOL and divertor at preventing impurities from contaminating the plasma core. The carbon fuelling efficiency is measured when a known amount of carbon is injected. That information is used to infer the contamination by intrinsic carbon sources, and to constrain code calculations about the fuelling efficiency. These same codes can be used to infer the carbon contamination in other machines [2] and other plasma conditions.

One unresolved aspect is the impact of SOL flows on the carbon fuelling efficiency. Large SOL flows have been observed in JET [3] and other devices $[4,5]$. The magnitude of the observed flows is presently not understood $[3,6$, and 7]. Consequently, the flows cannot be introduced into the models on a first-principles basis. The effect of the experimental flows on the SOL and the carbon fuelling is therefore unknown. Recent JET reverse magnetic field experiments [8] allowed methane screening experiments with reverse fields. This paper documents and models the SOL flow influence on the screening.

The experimental screening was unchanged when the fields were reversed while the SOL flows at the machine top reduced from a Mach number of 0.5 to near stagnation. The screening was modeled using EDGE2D/NIMBUS [9] where the flow was created by external forces acting upon the deuterium in the SOL. The required force was different for the forward and reverse field cases. The external force could also be applied to the carbon. The effect of the larger flow was to reduce the calculated carbon fuelling efficiency by about 5 to $15 \%$ indicating only a weak screening dependence on the SOL Mach number.

\section{Experiment}

A reciprocating Mach probe [3] measured the SOL flow at the vessel top. Both field directions have Mach numbers of about 0.2 at the separatrix, but differ at distances greater than $0.5 \mathrm{~cm}$ into the SOL [8] (fig.1). Normal field plasmas have peak Mach numbers of 0.5. Reverse field plasmas have a near stagnation point. This paper documents the carbon screening when the flow was changed by reversing the field.

The reverse field screening experiments reproduced normal field JET LMode discharges [1]. However, the Gas Box Divertor (Mk II GB) was used for the normal field experiments, and the Septum Replacement Divertor (Mk II GB SRP) was used for the reverse field experiments. Since the Gas Box carbon screening was insensitive to the divertor configuration [1], the different divertor configuration is assumed to not influence the results. 
Deuterated methane was puffed at the horizontal mid-plane for about $3 \mathrm{sec}$. A separate deuterium injection phase followed which produced a reference plasma condition of the same density but without the methane (fig. 2). The carbon content difference between $18 \mathrm{sec}$ and $22 \mathrm{sec}$ indicated the core carbon content due to the injected methane. The shot pair 49706 and 59598 had the same core density (fig. 2, 3 and Table I). The methane injection rate was about $30 \%$ higher in the normal field case. This difference occurred since the reverse field had increased wall fuelling causing higher density than the normal field plasmas with the same methane injection rate. To compare plasmas at the same core density, the reverse field plasma had lower methane injection rate than normal field plasma. The density and visible Bremsstrahung emission were similar both during the methane injection and the deuterium injection reference phase (fig. 3).

The raw data in figure 3 indicates that the $Z_{\text {eff }}$ and the charge exchange measured core carbon content increase were both larger in the normal field case in proportion to the difference in the methane injected rate. Thus the carbon fuelling efficiency was similar for normal and reverse field. The carbon fuelling efficiency [1] is defined as $\mathrm{FE}=\Delta \mathrm{N}_{\mathrm{C}} /\left(\Gamma_{\mathrm{C}} \tau_{\mathrm{p}}{ }^{*}\right)$.

\section{Results}

The L-Mode screening for methane injected at the horizontal mid-plane was similar in reverse and normal field. The carbon screening was insensitive to the SOL flow change in Fig. 1. The density and applied power were varied for the reverse field plasmas. For methane injected at the horizontal mid-plane, the reverse field screening also fit the normal field regression [1] (fig. 4). The $Z_{\text {eff }}$ differencing uncertainties [1] were similar for both field directions and dominate the error bars in figure 4. Normal field plasmas (equation (5) of [1]) had decreased carbon fuelling efficiency at higher density and lower energy confinement. The reverse field data showed the same trends as the normal field data, with less variation on the achieved density, due to the higher wall source, and more variation in the applied power, due to the lack of an H-Mode.

The poloidal variation of the carbon fuelling efficiency was obtained by puffing the methane from other gas injection valves (fig. 5). The poloidal variation of the carbon fuelling efficiency was similar but not identical to the distribution observed with normal field. Compared to normal field operation, the divertor was better screened and the top of the device worse screened.

\section{Modeling}

Two plasmas with similar density and energy confinement were chosen for experimental comparison (Table I) and EDGE2D modeling. EDGE2D/NIMBUS models the JET SOL using fluid equations with a Monte Carlo treatment of the deuterium and carbon neutrals [9]. The only carbon introduced into these simulations was $0.36 \mathrm{eV}$ injected carbon neutrals [1] 
intended to simulate the carbon from the methane. The known forces in the fluid modeling cannot account for the observed flows [3]. Therefore, an external force was applied to create the SOL flows.

The force was applied parallel to the field lines, from below the horizontal mid-plane to the vessel top, and from the separatrix to a $2 \mathrm{~cm}$ mid-plane SOL depth (fig. 1). A peak force acting on the deuteron ions of $+9 \mathrm{nt} / \mathrm{m}^{3}$ for normal field, and $-3 \mathrm{nt} / \mathrm{m}^{3}$ for the reverse field was required to account for the SOL flow. The externally applied force is about twice as large as the sum of the parallel thermal force, the frictional force between the deuterium and the carbon, and the $\underline{\mathrm{E} X} \underline{\mathrm{B}}$ and diamagnetic forces that make up the PfirschSchluter current. All these forces are included in the EDGE2D calculation.

The resulting flow agreed reasonably with the experimental values between the separatrix and $4 \mathrm{~cm}$ mid-plane depth in the SOL at the location where it was measured near the vessel top (fig. 1). The flow in the entire SOL is complicated, and measurement in just one location is not adequate to constrain the calculations. In this paper, a minimum poloidal extent was used to achieve agreement with the mach probe measurements. The effects of a more extended poloidal force have not yet been studied.

In some models, the force was only applied to the deuterium. On these runs, the carbon experiences the applied force through the frictional coupling to the deuterons. On other runs, an external force was applied to the carbon as well. That force was distributed over the charge states according to their relative density. A force on each carbon equal to the force on each deuteron, caused a further $10 \%$ reduction in the normal field carbon fuelling efficiency, but did not change the reversed field fuelling efficiency (Table I). The forces quoted in table I are the total force integrated over the species density.

The carbon fuelling efficiency was 5 to $15 \%$ higher in the reverse field simulation (Table I) which is less than the experimental resolution (error bars in figure 4). Consequently, the modeling indicates little change in the predicted carbon fuelling efficiency in spite of the considerable change in the SOL flow pattern (figure 1). Plausibly, the carbon exhaust from the main chamber SOL is controlled by the carbon flow velocity into the divertor. That flow is calculated to be dominated by the thermal force (fig. 6) which was relatively unchanged by the application of the external force. Thus the lack of a change in the carbon fuelling efficiency might indicate that the flow drive mechanism does not act near the divertor throat.

The location of the carbon injection was varied in separate code runs. The carbon fuelling efficiency changed in a manner similar but not identical to the experimental data (fig. 5). The reverse field simulations had systematically higher carbon fuelling efficiency at both the divertor and the machine top. 
The higher flow velocity (normal field) was calculated to modify the SOL density profile, causing a steeper density gradient (table I). The normal field deuterium gas injection rate was required to be $30 \%$ higher to achieve the same separatrix density. The SOL density profile changed is quantified in table I by the density $2 \mathrm{~cm}$ from the mid-plane separatrix. That density was $30 \%$ lower with the higher SOL flow. The code runs were matched to the separatrix density. The SOL density profile influences the location of carbon ionization, and with the higher flow having a thinner SOL, the carbon is ionized closer to the separatrix, so that the flow effect on screening might be larger than presently depicted.

\section{Discussion}

The JET reverse field experiments indicated that carbon screening was not changed by the JET SOL flow changes. The experimental results differ from previous DIII-D H-Mode experiments [10]. We attribute that difference to the difference in plasma regimes since the JET results are in L-Mode.

The JET results were modeled by EDGE2D indicating that little change in the screening might occur since the escape of the carbon from the main chamber SOL into the divertor is controlled by the thermal force acting at the divertor entrance. A force acting upon the carbon equal to the deuterium force only modestly changed the screening. These code results differ from previous DIVIMP modeling [1] which predicted a larger change in the screening. Probably, DIVIMP used too simple a flow model since a poloidally and radially constant carbon flow velocity was applied to the entire SOL region.

This work has been conducted under the European Fusion Development Agreement and is partly funded by Euratom and the US Department of Energy 
References:

[1] J.D.Strachan, et al, Nuclear Fusion, 43, 922 [2003]

[2] J.D.Strachan, et al, Nuclear Fusion, to be published

[3] S.K.Erents, et al, Pl. Phys. Control. Fusion, 42, 905 [2000]

[4] N.Asakura, et al, Nuclear Fusion 39, 1983 [1999]

[5] B. laBombard, et al, J. Nucl. Mater. 241-243, 149 [1997]

[6] G.D.Porter, et al, J. Nucl. Mater. 313-316, 1085 [2003]

[7] V.Rozhansky, et al, J. Nucl. Mater. 313-316, 1141 [2003]

[8] R.A.Pitts, et al, BAPS $\underline{48}$, No. 7, LO1 3 [2003]

[9] R.Simonini, et al, Contrib. Plasma Phys. 34, 368 [1994]

[10]W. P. West, et al, J. Nucl. Mater. 313-316, 1211 [2003] 
Table I. Experimental and EDGE2D simulation results compared for the normal field and reverse field cases. The volume averaged density was used to match the experimental shots, while the separatrix density was used to match the models. For JET L-Mode plasmas the separatrix density is often about 1/3 of the volume averaged density.

\begin{tabular}{|c|c|c|c|c|c|c|}
\hline parameter & 49706 & 59598 & EDGE2D & EDGE2D & EDGE2D & EDGE2D \\
\hline field & normal & reverse & normal & reverse & normal & reverse \\
\hline $\mathrm{M}($ at $2 \mathrm{~cm})$ & .57 & .02 & 0.52 & -.02 & .53 & -.02 \\
\hline $\begin{array}{c}\mathrm{D}+\text { force } \\
\left(\mathrm{nt} / \mathrm{m}^{3}\right)\end{array}$ & ---- & ---- & 9 & -3 & 9 & -3 \\
\hline $\begin{array}{c}\mathrm{C} \text { force } \\
\left(\mathrm{nt} / \mathrm{m}^{3}\right)\end{array}$ & ---- & ---- & 0 & 0 & 1.0 & -.9 \\
\hline $\begin{array}{c}<\mathrm{n}_{\mathrm{e}}> \\
\left(10^{19} / \mathrm{m}^{3}\right)\end{array}$ & 2.4 & 2.5 & ---- & ---- & ---- & ---- \\
\hline $\mathrm{n}_{\mathrm{SEP}}\left(10^{19} / \mathrm{m}^{3}\right)$ & ---- & ---- & .8 & .86 & .85 & .85 \\
\hline $\mathrm{n}_{2 \mathrm{CM}}\left(10^{19} / \mathrm{m}^{3}\right)$ & ----- & ---- & .28 & .4 & .28 & .4 \\
\hline$\Gamma_{\mathrm{C}}\left(10^{21} / \mathrm{s}\right)$ & 2.2 & 1.38 & 1.5 & 1.5 & 1.5 & 1.5 \\
\hline$\tau_{\mathrm{E}}(\mathrm{s})$ & .5 & .5 & .67 & .67 & .67 & .67 \\
\hline $\mathrm{FE}(\%)$ & 5.6 & 4.6 & 5.25 & 5.53 & 4.76 & 5.33 \\
\hline
\end{tabular}


Figure captions:

Figure 1. The Mach number simulated by EDGE2D (lines) and average values measured by the JET reciprocating probe [8]. The dashed lines are the external deuterium forces with no force acting on the carbon (Table I).

Figure 2. Time evolution of the applied power, the electron injection rates of $\mathrm{CD}_{4}$ and $\mathrm{D}_{2}$, and the power radiated from the core and the total including the $\mathrm{X}$-point region for the cases in Table I and figure 1.

Figure 3. Time evolution of the volume averaged electron density, the lineaveraged electron density, visible Bremsstrahlung intensity, VB deduced $Z_{\text {eff }}$, and the charge exchange deduced total carbon content in the core. The two plasmas are the normal and reverse field plasmas of figures 1 and 2 and Table I.

Figure 4. The carbon fuelling efficiency for the reverse field L-Mode plasmas plotted against the normal field empirical scaling [1]. The uncertainty arises primarily from the differencing of the $\mathrm{Z}_{\text {eff }}$ values (fig. 3).

Figure 5. The carbon fuelling efficiency normalized to the mid-plane normal field scaling [1] plotted against the poloidal angle of methane injection. The line connects the normal field experimental results.

Figure 6 . The EDGE2D average carbon velocity was little changed at the inner and outer divertor entrances for cases with only an external deuterium force. 


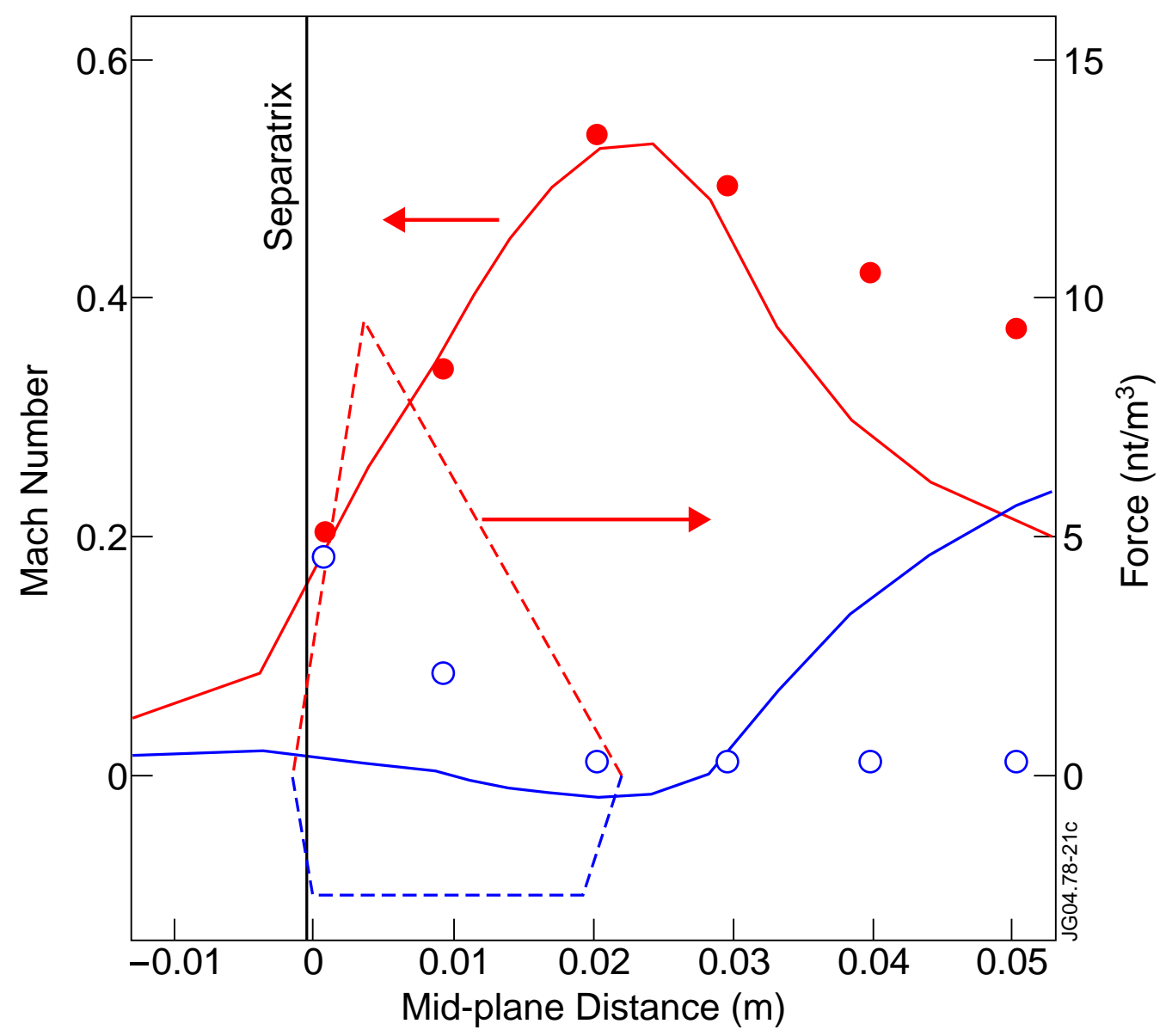

Figure 1 


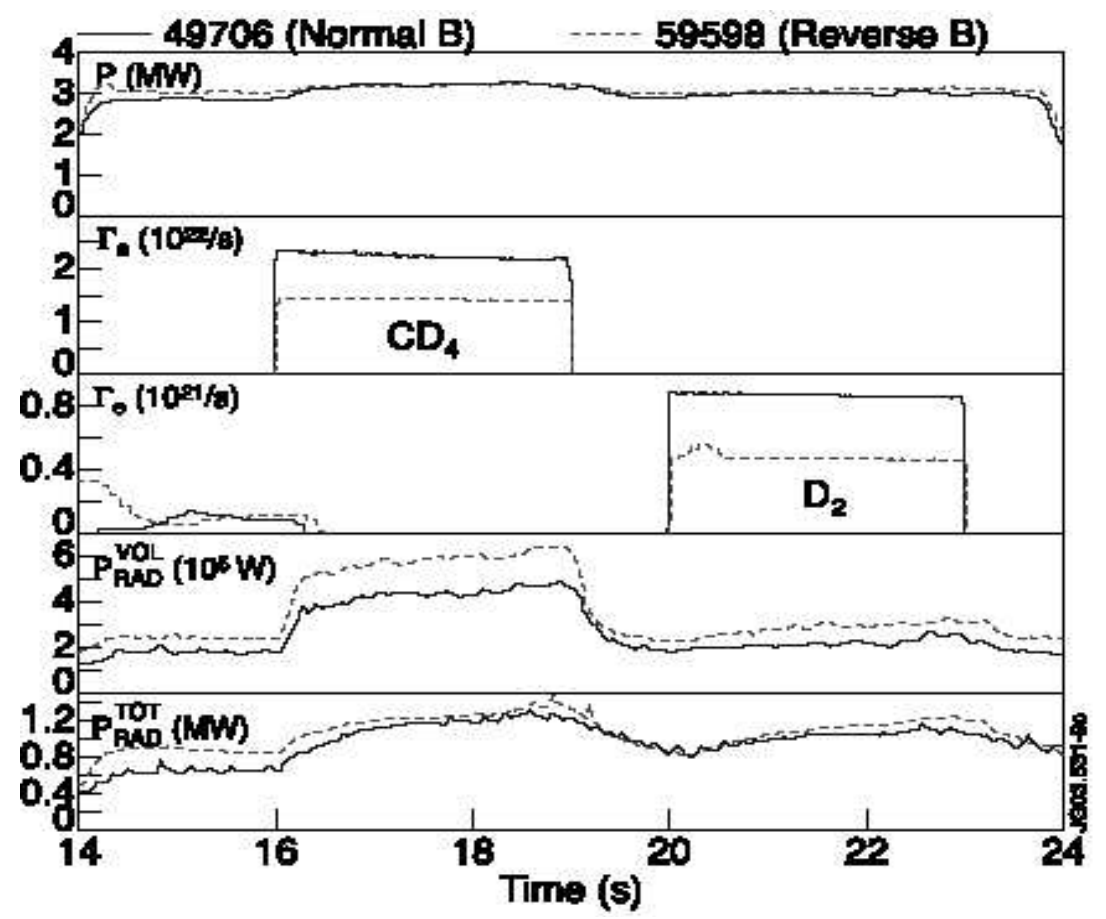

Figure 2. 


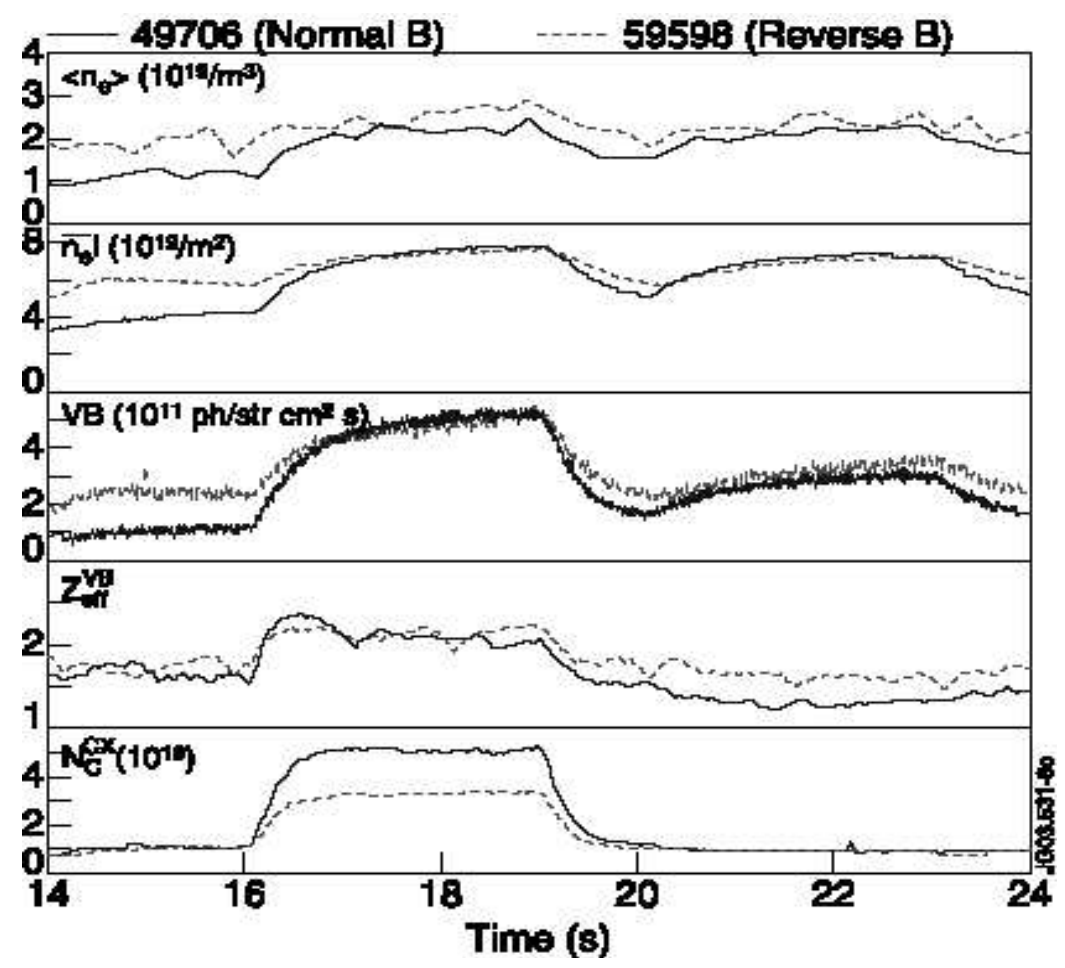

Figure 3. 


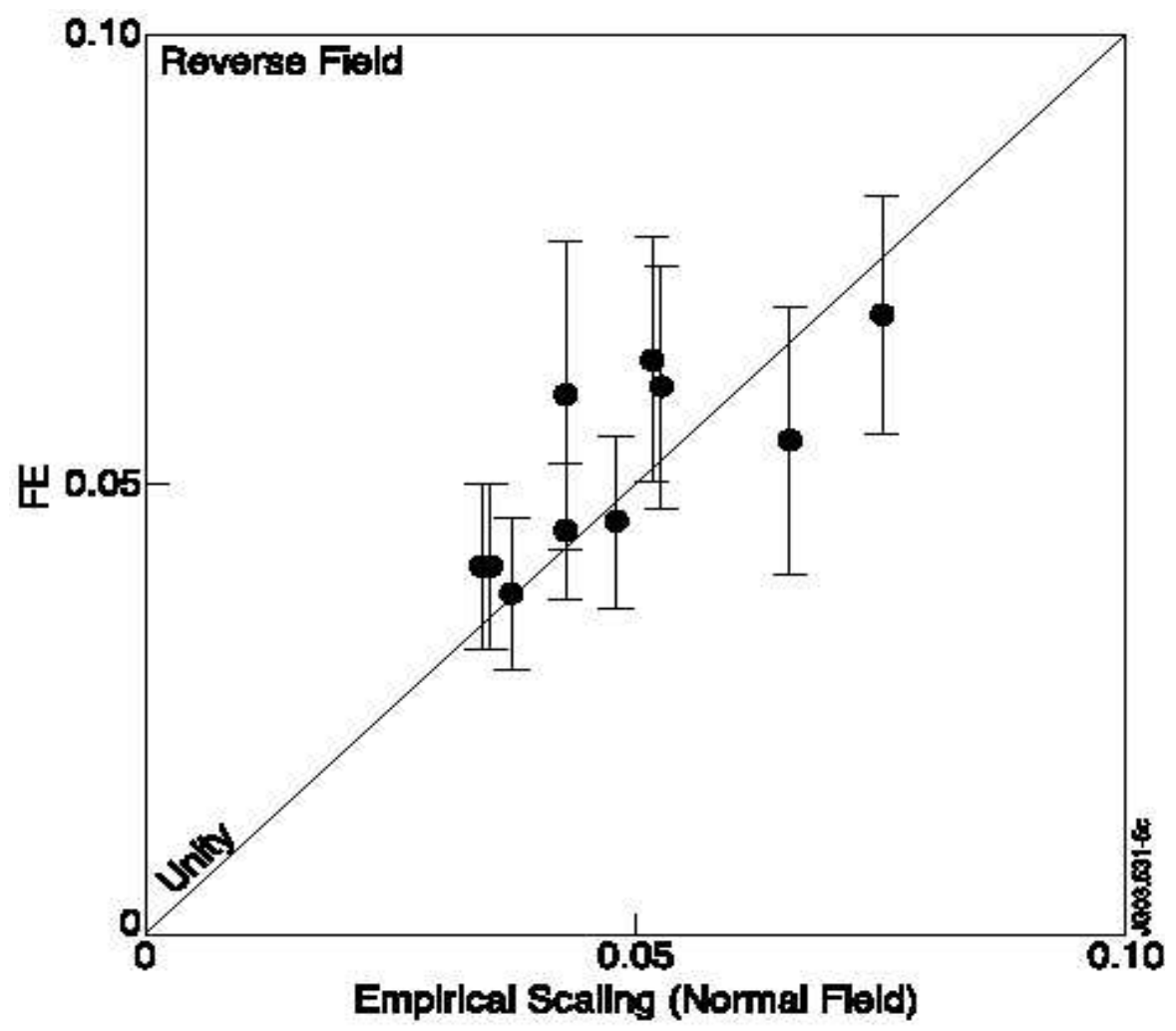

Figure 4. 


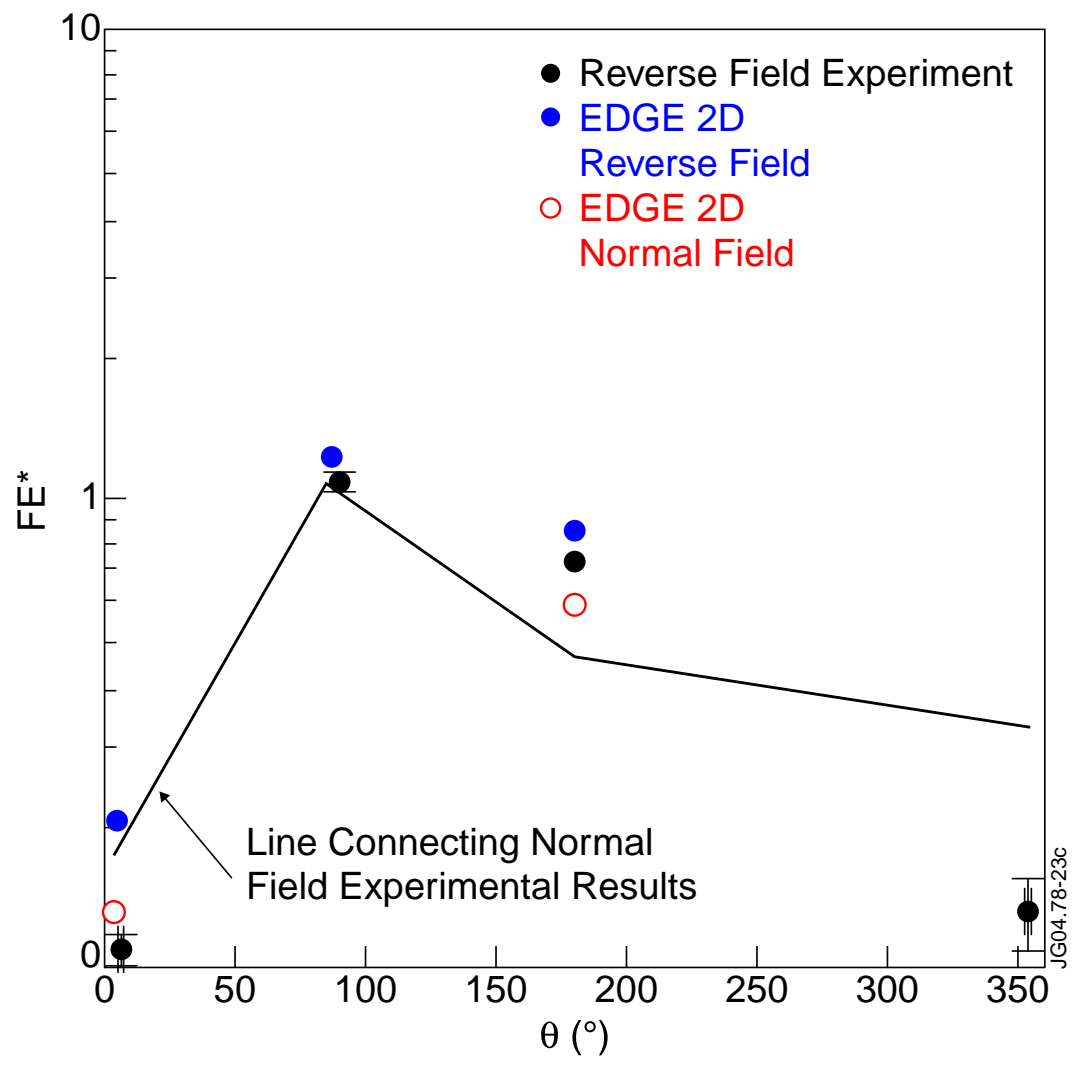

Figure 5 


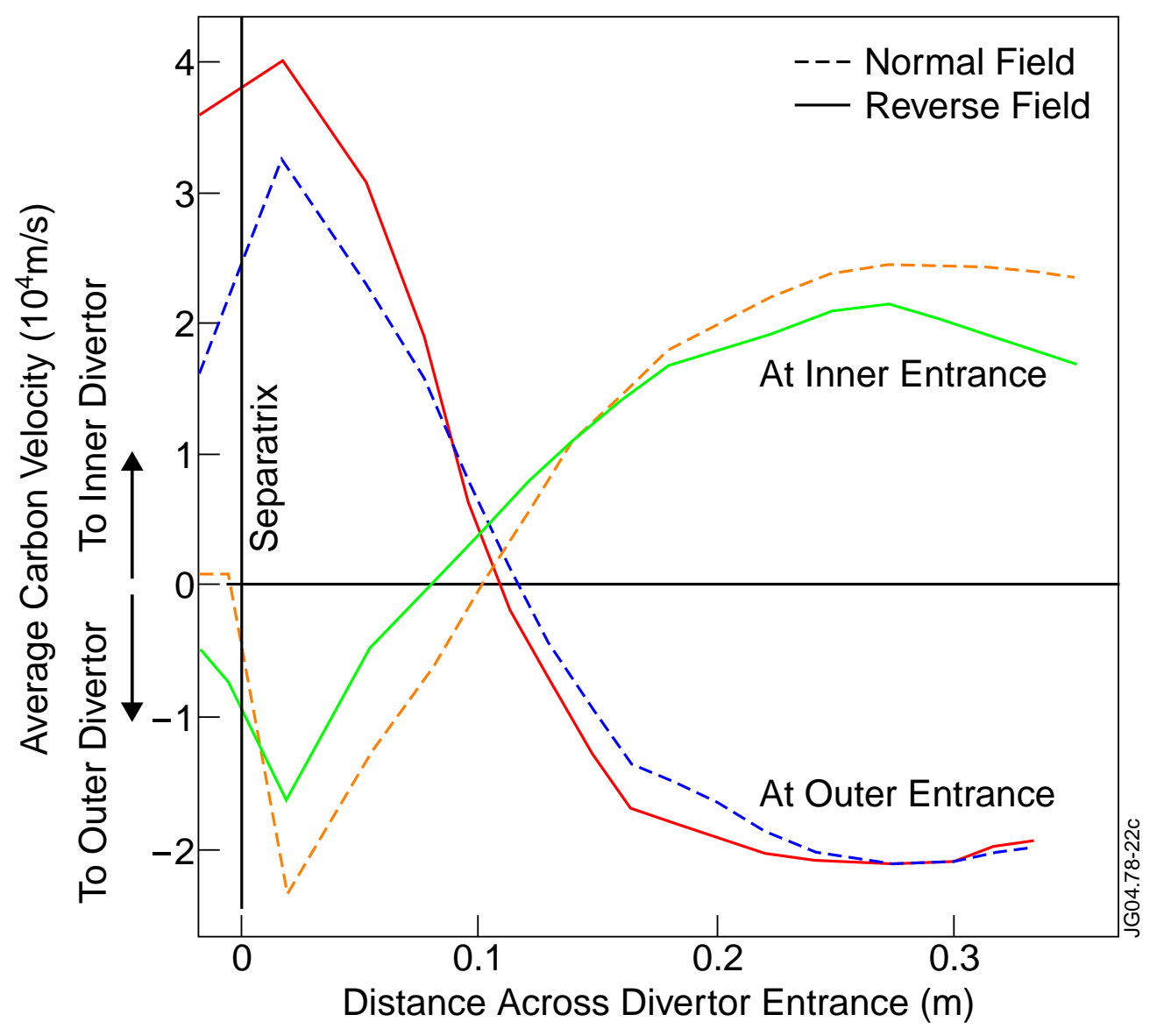

Figure 6 


\section{External Distribution}

Plasma Research Laboratory, Australian National University, Australia

Professor I.R. Jones, Flinders University, Australia

Professor João Canalle, Instituto de Fisica DEQ/IF - UERJ, Brazil

Mr. Gerson O. Ludwig, Instituto Nacional de Pesquisas, Brazil

Dr. P.H. Sakanaka, Instituto Fisica, Brazil

The Librarian, Culham Laboratory, England

Mrs. S.A. Hutchinson, JET Library, England

Professor M.N. Bussac, Ecole Polytechnique, France

Librarian, Max-Planck-Institut für Plasmaphysik, Germany

Jolan Moldvai, Reports Library, Hungarian Academy of Sciences, Central Research Institute for Physics, Hungary

Dr. P. Kaw, Institute for Plasma Research, India

Ms. P.J. Pathak, Librarian, Institute for Plasma Research, India

Ms. Clelia De Palo, Associazione EURATOM-ENEA, Italy

Dr. G. Grosso, Instituto di Fisica del Plasma, Italy

Librarian, Naka Fusion Research Establishment, JAERI, Japan

Library, Laboratory for Complex Energy Processes, Institute for Advanced Study, Kyoto University, Japan

Research Information Center, National Institute for Fusion Science, Japan

Dr. O. Mitarai, Kyushu Tokai University, Japan

Dr. Jiangang Li, Institute of Plasma Physics, Chinese Academy of Sciences, People's Republic of China

Professor Yuping Huo, School of Physical Science and Technology, People's Republic of China

Library, Academia Sinica, Institute of Plasma Physics, People's Republic of China

Librarian, Institute of Physics, Chinese Academy of Sciences, People's Republic of China

Dr. S. Mirnov, TRINITI, Troitsk, Russian Federation, Russia

Dr. V.S. Strelkov, Kurchatov Institute, Russian Federation, Russia

Professor Peter Lukac, Katedra Fyziky Plazmy MFF UK, Mlynska dolina F-2, Komenskeho Univerzita, SK-842 15 Bratislava, Slovakia

Dr. G.S. Lee, Korea Basic Science Institute, South Korea

Institute for Plasma Research, University of Maryland, USA

Librarian, Fusion Energy Division, Oak Ridge National Laboratory, USA

Librarian, Institute of Fusion Studies, University of Texas, USA

Librarian, Magnetic Fusion Program, Lawrence Livermore National Laboratory, USA

Library, General Atomics, USA

Plasma Physics Group, Fusion Energy Research Program, University of California at San Diego, USA

Plasma Physics Library, Columbia University, USA

Alkesh Punjabi, Center for Fusion Research and Training, Hampton University, USA

Dr. W.M. Stacey, Fusion Research Center, Georgia Institute of Technology, USA

Dr. John Willis, U.S. Department of Energy, Office of Fusion Energy Sciences, USA

Mr. Paul H. Wright, Indianapolis, Indiana, USA 
The Princeton Plasma Physics Laboratory is operated by Princeton University under contract with the U.S. Department of Energy.

\author{
Information Services \\ Princeton Plasma Physics Laboratory \\ P.O. Box 451 \\ Princeton, NJ 08543
}

Phone: 609-243-2750

Fax: 609-243-2751

e-mail: pppl_info@pppl.gov

Internet Address: http://www.pppl.gov 